\title{
Fe-Pt Thick Film Magnets Prepared by High-Speed PLD Method
}

\author{
M. Nakano, S. Shibata, T. Yanai, and H. Fukunaga \\ Department of Electrical Engineering and Electronics, Nagasaki University, Nagasaki, 852-8521 Japan
}

\begin{abstract}
$\mathrm{Fe}_{50} \mathrm{Pt}_{50}$ film magnets were prepared by the pulsed laser deposition (PLD) method under the high deposition rate. Increase in a laser power enabled us to increase the deposition rate and obtain Fe-Pt thick films with good mechanical properties. The maximum deposition rate of $50 \mu \mathrm{m} / \mathrm{h}$ can be achieved at the laser power of $9 \mathrm{~W}$. Although a substrate heating system was not comprised in our PLD apparatus, the substrate temperature showed higher than $673 \mathrm{~K}$ as the laser power exceeded $5 \mathrm{~W}$. In the as-deposited films prepared under the laser power ranging between 5 and $9 \mathrm{~W}$, order-disorder transformation occurred and the values of coercivity of the samples became higher than $400 \mathrm{kA} / \mathrm{m}$.
\end{abstract}

Index Terms - Fe-Pt thick film magnets, order-disorder transformation, pulsed laser deposition (PLD) method.

\section{INTRODUCTION}

$\mathbf{F}$ ePt film with ordered face-centered-tetragonal (fct) structure has received significant attention due to their large magnetocrystalline anisotropy and attractive magnetic properties [1]-[4], for example Weisheit et al. reported laser-deposited Fe-Pt films with high coercivity up to $5.6 \mathrm{~T}$ [3], [4]. Each thickness of the-above-mentioned films, however, is less than $1 \mu \mathrm{m}$ because the main application is perpendicular recording media. In order to apply Fe-Pt film magnets for medical micro-machines and dental attachment [5], the films with high energy product and thickness of several tens of micro-meters are needed. A dominant method for obtaining Fe-Pt thick films is a sputtering. For example, Aoyama et al. [6] reported a 129 $\mu$ m-thick film with $\mathrm{Hc}=580 \mathrm{kA} / \mathrm{m}$ and $(\mathrm{BH})_{\max }=104$ $\mathrm{kJ} / \mathrm{m}^{3}$ [3], and a $7 \mu \mathrm{m}$-thick Fe-Pt film was reported by Liu et al. to have magnetic properties with $\mathrm{Hc}=446 \mathrm{kA} / \mathrm{m}$ and $(\mathrm{BH})_{\max }=124 \mathrm{~kJ} / \mathrm{m}^{3}$ [7]. The sputtering method, however, includes the difficulty of deposition speed for a mass-production of the above-mentioned miniaturized devices.

This contribution reports PLD-fabricated $\mathrm{Fe}_{50} \mathrm{Pt}_{50}$ thick films under the high deposition rate up to approximately $50 \mu \mathrm{m} / \mathrm{h}$. Resultantly, coercivity and $(\mathrm{BH})_{\max }$ values of an as-deposited film prepared at the laser power of $8 \mathrm{~W}$ were $442 \mathrm{kA} / \mathrm{m}$ and 68 $\mathrm{kJ} / \mathrm{m}^{3}$ [3], respectively.

\section{EXPERIMENTAL}

A schematic diagram for the PLD method was shown in Fig. 1. A Fe-Pt target with the composition of $\mathrm{Fe}_{60} \mathrm{Pt}_{40}$ was ablated with a Nd-YAG pulse laser at the repetition rate of $30 \mathrm{~Hz}$, and the films were deposited on Ta substrates whose thickness was $40 \mu \mathrm{m}$. Before the ablation, the chamber was evacuated down to approximately $0.1 \mathrm{mPa}$ with a molecular turbo pump. The distance between a target and a substrate was fixed at $10 \mathrm{~mm}$. The area and composition of all the obtained films were $5 \times 5 \mathrm{~mm}$ [2] and approximately $\mathrm{Fe}_{50} \mathrm{Pt}_{50}$, respectively. The deposition rate was varied by controlling the laser

Digital Object Identifier 10.1109/TMAG.2008.2001883

Color versions of one or more of the figures in this paper are available online at http://ieeexplore.ieee.org.

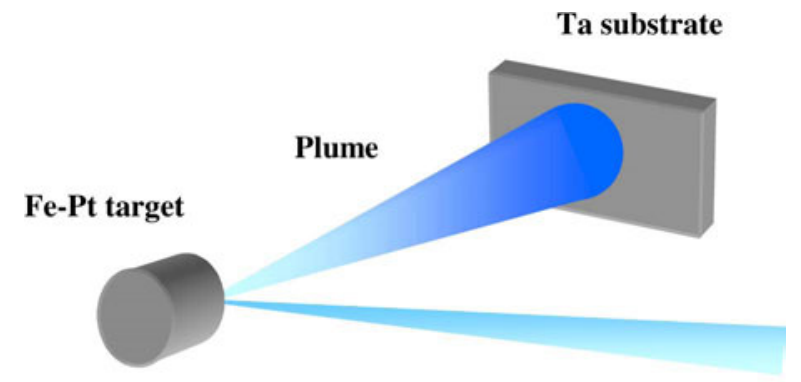

Pulse laser

Fig. 1. Schematic diagram for PLD method. The distance between a target and a substrate was fixed at $10 \mathrm{~mm}$. A Fe-Pt target was ablated with a Nd-YAG pulse laser at the repetition rate of $30 \mathrm{~Hz}$, and the films were deposited on Ta substrates.

power between 1 and $9 \mathrm{~W}$ at the irradiation exit of a Nd-YAG laser system. The thickness ranging from 2 to $50 \mu \mathrm{m}$ can be obtained. As-deposited samples prepared by the laser power less than $4 \mathrm{~W}$ were post-annealed at various temperatures in order to obtain ordered phase and hard magnetic properties. We set the heating rate and holding time at $100 \mathrm{~K} / \mathrm{min}$ and $10 \mathrm{~min}$, respectively.

After a sample was magnetized up to $7 \mathrm{~T}$ with a pulse magnetizer, magnetic properties were measured with a vibrating sample magnetometer which could apply a magnetic field up to approximately $1800 \mathrm{kA} / \mathrm{m}$ reversibly. In-plane magnetic properties were shown in this paper. The analysis of crystal structure was carried out with an X-ray diffractometer (XRD) and the average thickness was measured with a micrometer.

\section{RESULTS AND DISCUSSION}

Fig. 2 shows the thickness of Fe-Pt film magnets as a function of the laser power. As the power increased, the obtained thickness increased, and the deposition rate was proportional to the laser power. The wide control for the deposition rate can be succeeded in our PLD system, and the maximum value of $50 \mu \mathrm{m} / \mathrm{h}$ was approximately 10 times as large as that reported by Aoyama [6]. Although the surface roughness increased with the increase in laser power and deposition rate, a peeling phenomenon was not observed in all the as-deposited films. These results indicate that the high-speed PLD method enabled us to obtain Fe-Pt thick films with good mechanical properties under the high deposition rate. In Fig. 3, the relationship between the 


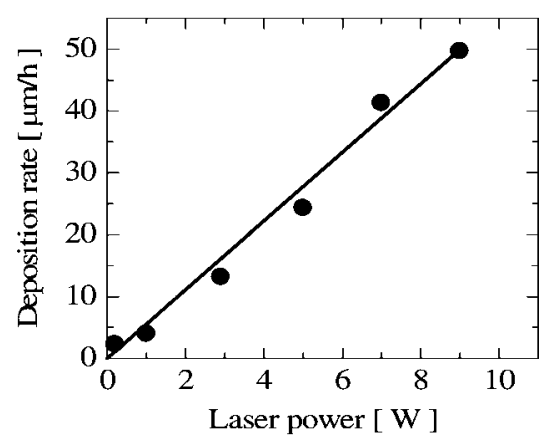

Fig. 2. Deposition rate as a function of laser power. The laser power was measured at the irradiation exit of an Nd-YAG laser apparatus. The deposition rate increased with increasing the laser power. The maximum value of $50 \mu \mathrm{m} / \mathrm{h}$ can be achieved at the laser power of $9 \mathrm{~W}$.

laser power and coercivity for the as-deposited films was indicated. The thickness ranging was between approximately 2 and $50 \mu \mathrm{m}$. The power higher than $5 \mathrm{~W}$ drastically boosted the coercivity, and the values exceeded $400 \mathrm{kA} / \mathrm{m}$ which is comparable with those of Fe-Pt sputtered thick film magnets [6], [7]. In order to investigate the mechanism for obtaining the films with the large coercivity, X-ray diffraction patterns were observed for the same samples displayed in Fig. 4. When the laser power was $3 \mathrm{~W}$, the samples consisted of a soft face-centered cubic (fcc) phase. With increasing the power from 3 to $8.5 \mathrm{~W}$, the film experienced a phase transformation from a disordered soft phase to an ordered hard face-centered tetragonal (fct) phase. In our experiment, although a substrate heating system was not used, the temperature on a substrate showed higher than $678 \mathrm{~K}$ as the power exceeded $5 \mathrm{~W}$. It is considered that the high substrate temperature is attributed to radiant heat from a target and that the substrate heat treatment resulted in the large coercivity due to the fct phase. Fig. 5 shows an M-H loop of an as-deposited film prepared at the laser power of $8 \mathrm{~W}$. The values of coercivity, remanence and $(\mathrm{BH})_{\max }$ were $442 \mathrm{kA} / \mathrm{m} 0.69 \mathrm{~T}$ and 68 $\mathrm{kJ} / \mathrm{m}^{3}$ [3], respectively. The value of saturation magnetization of $\mathrm{Fe}_{50} \mathrm{Pt}_{50}$ with ordered phase is approximately $1.4 \mathrm{~T}$, therefore the obtained remanence in Fig. 5 agreed with a theoretical value of $0.7 \mathrm{~T}$ in an isotropic $\mathrm{Fe}_{50} \mathrm{Pt}_{50}$ film. It is generally reported [7] that a remanence enhancement due to a exchange interaction between the hard magnetic fct phases occurred and the value of remanence showed higher than $0.7 \mathrm{~T}$ in the Fe-Pt sputtered films. In the obtained PLD-fabricated samples, however, the enhancement effect is considered to be little compared with those of the sputtering-fabricated samples. In addition, the samples shown in Fig. 3 had the wide thickness ranging from 2 to 50 $\mu \mathrm{m}$, therefore we need to investigate the thickness dependence on magnetic properties as a future work.

As shown in Figs. 3 and 4, the as-deposited films prepared by the laser power lower than $4 \mathrm{~W}$ had low coercivity and mainly consisted of the fcc phases. In order to obtain the phase transformation from fcc to fct phase, a post-annealing was carried out for a film prepared at the laser power of 2 W. Fig. 6 shows the coercivity as a function of the post-annealing temperature. In the samples annealed at 573 and $673 \mathrm{~K}$, the coercivitiy values

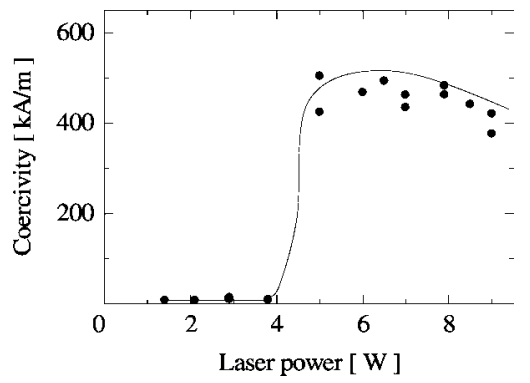

Fig. 3. Coercivity values of Fe-Pt thick films prepared under various laser powers laser powers. The value of coercivity drastically increased as the power exceeded $5 \mathrm{~W}$.

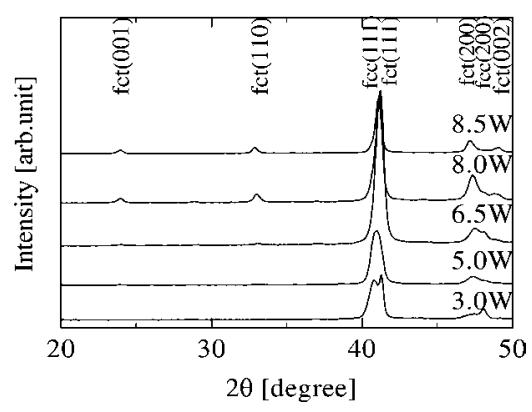

Fig. 4. X-ray diffraction patterns for as-deposited films prepared under various laser powers. With increasing the laser power, order-disorder transformation occurred. In the laser power higher than $5 \mathrm{~W}$, the substrate temperature showed higher than $678 \mathrm{~K}$ due to radiant heat from a target.

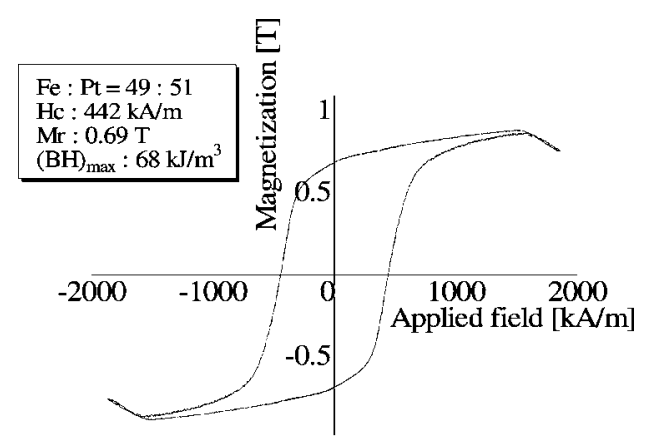

Fig. 5. In-plane M-H loop of an as-deposited film prepared at the laser power of $8 \mathrm{~W}$. The values of coercivity, remanence and $(\mathrm{BH})_{\max }$ were $442 \mathrm{kA} / \mathrm{m} 0.69$ $\mathrm{T}$ and $68 \mathrm{~kJ} / \mathrm{m}^{3}$ [3], respectively.

exceeded $400 \mathrm{kA} / \mathrm{m}$. As the temperature became higher than approximately $700 \mathrm{~K}$, the values of coercivity decreased. As seen in X-ray diffraction patterns, the increase in temperature leaded the appearance of the peaks corresponding to fct(001) and (110) phases. Namely, the increase in coercivity shown during 473 and $673 \mathrm{~K}$ is attributed to the order-disorder transformation Fig. 7. On the other hand, the decrease of coercivity during 673 and $873 \mathrm{~K}$ is considered to be the reduction in the c-axis variant boundaries and order-disordered phase boundaries due to the grain growth [7], [8].

In order to investigate the relationship between the magnetic properties and the above-mentioned fabrication processes, the microstructure analysis is needed. 


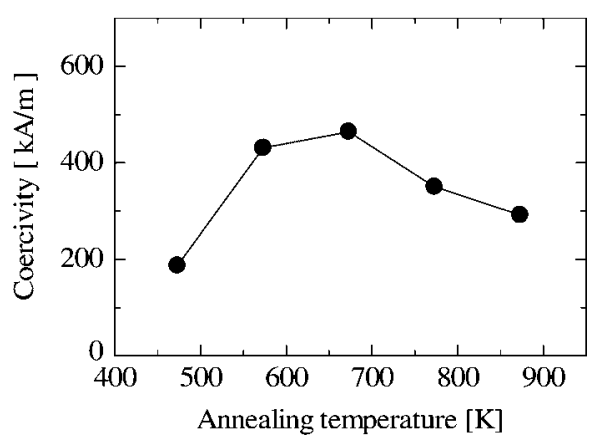

Fig. 6. Coercivity as a function of post-annealing temperature. As-deposited films prepared at the laser power of $2 \mathrm{~W}$ were post-annealed with an infrared furnace. The heating rate and holding time were $100 \mathrm{~K} / \mathrm{min}$ and $10 \mathrm{~min}$, respectively.

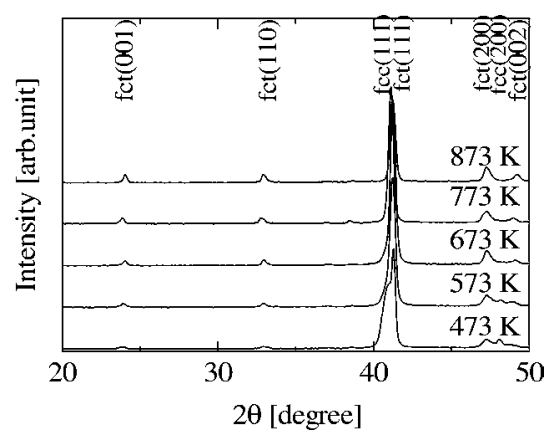

Fig. 7. X-ray diffraction patterns for shown in Fig. 6. With increasing the temperature of post-annealing, the film experienced a phase transformation from the disordered soft magnetic phase (fcc) to an ordered hard magnetic phase (fct).

\section{CONCLUSION}

The high-speed PLD method with the maximum deposition rate of $50 \mu \mathrm{m} / \mathrm{h}$ enabled us to obtain Fe-Pt thick films with the thickness ranging from 2 to $50 \mu \mathrm{m}$. In the as-deposited films prepared under the laser power ranging between 5 and $9 \mathrm{~W}$, order-disorder transformation occurred and the values of coercivity of the samples showed higher than $400 \mathrm{kA} / \mathrm{m}$ without a post-annealing process.

\section{ACKNOWLEDGMENT}

This work was supported in part by the Ministry of Education, Science, Sports and Culture of Japan under a Grand-in-Aids (19360147).

\section{REFERENCES}

[1] T. Shima, K. Takanashi, Y. K. Takahashi, and K. Hono, "Preparation and magnetic properties of highly coercive FePt films," Appl. Phys. Lett., vol. 81, pp. 1050-1052, 2002.

[2] A. Breitling and D. Goll, "Hard magnetic L1 ${ }_{0} \mathrm{FePt}$ thin film and nanopatterns," J. Magn. Magn. Mater., vol. 320, pp. 1449-1456, 2008.

[3] M. Weisheit, L. Schultz, and S. Fahler, "Textured growth of highly coercive $\mathrm{L} 1_{0}$ ordered FePt thin films on single crystalline amd amorphous substrates," J. Appl. Phys., vol. 95, pp. 7489-7491, 2004.

[4] M. Weisheit, L. Schultz, and S. Fahler, "On the influence of composition on laser-deposited Fe-Pt films," J. Magn. Magn. Mater., vol. 290-291, pp. 570-572, 2005.

[5] H. Aoyama and Y. Honkura, "Aichi Steel Corporation," United States Patent, 10/086 454, 2002.

[6] H. Aoyama and Y. Honkura, "Magnetic properties of Fe-Pt sputtered thick film magnet," J. Magn. Soc. Japan, vol. 20, pp. 237-240, 1996, (in Japanese).

[7] W. F. Liu, S. Suzuki, D. S. Li, and K. Machida, "Magnetic properties of Fe-Pt thick film magnets prepared by RF sputtering," J. Magn. Magn. Mater., vol. 302, pp. 201-205, 2006.

[8] H. Ito, T. Kusunoki, H. Saito, and S. Ishio, " $\mathrm{L} 1_{0}$ ordering thin films by rapid thermal annealing," J. Magn. Soc. Japan, vol. 27, pp. 1083-1086, 2003, (in Japanese).

Manuscript received March 03, 2008. Current version published December 17, 2008. Corresponding author: M. Nakano (e-mail: mnakano@nagasaki-u.ac. jp). 